\title{
EFICIÊNCIA DE UM NOVO INSETICIDA COMERCIAL PARA O CONTROLE DO CASCUDINHO DOS AVIÁRIOS (ALPHITOBIUS DIAPERINUS) (PANZER) (COLEOPTERA: TENEBRIONIDAE)
}

\author{
L.FA. Alves ${ }^{1}$, D.H. Uemura-Lima ${ }^{1}$, D.G.P. de Oliveira ${ }^{2}$, R.P.V. Godinho ${ }^{3}$ \\ ${ }^{1}$ Universidade Estadual do Oeste do Paraná, Centro de Ciências Biológicas e da Saúde, Laboratório de \\ Zoologia de Invertebrados, CP 711, CEP 85819-110, Cascavel, PR, Brasil. E-mail: 1faalves@unioeste.br
}

\section{RESUMO}

\begin{abstract}
O presente estudo foi realizado com o objetivo de avaliar em condições de laboratório e campo, a eficiência de um inseticida Teste (à base de cipermetrina, clorpirifós e citronela), no controle do cascudinho dos aviários (Alphitobius diaperinus). Em laboratório, o produto foi testado sobre insetos adultos, por meio de pulverização sobre os insetos (contato direto) e caminhamento sobre superfície tratada (contato indireto). Posteriormente, foi avaliado em condições de campo, em um aviário de frangos de corte. O produto foi eficiente, sendo comparável ao produto padrão, causando $100 \%$ de mortalidade em laboratório e reduzindo a população do aviário em $76 \%$. Assim, o produto constitui-se em uma alternativa para o controle do cascudinho.
\end{abstract}

PALAVRAS-CHAVE: Controle químico, produção animal, avicultura, frango de corte.

\section{ABSTRACT}

EFFECTIVENESS OF A NEW COMMERCIAL INSECTICIDE FOR THE CONTROL OF THE LESSERMEALWORM(ALPHITOBIUSDIAPERINUS)(PANZER)(COLEOPTERA:TENEBRIONIDAE). The present study was carried out with the objective to evaluate, under laboratory and field conditions, the effectiveness of the insecticide Test (based on cypermethrin, chlorpyrifos and citronellal), for the control of lesser mealworm (Alphitobius diaperinus). In the laboratory, the product was tested on adult insects, by spraying on the insects (direct contact) and by their walking on a treated surface (indirect contact). After this, it was evaluated in field conditions, in a poultry house. The product was effective, being comparable to the standard product, causing $100 \%$ of mortality in the laboratory and reducing the population in the poultry house by $76 \%$. Thus, the product presents an alternative for the control of this pest.

KEY WORDS: Chemical control, animal production, aviculture, broiler chicken.

\section{INTRODUÇÃO}

Alphitobius diaperinus (Panzer, 1797) (Coleoptera: Tenebrionidae), conhecido como cascudinho, é comumente encontrado em altas populações no substrato dos aviários, alimentando-se de ração e em carcaças de aves mortas, sendo considerado um dos principais problemas das criações comerciais de aves em todo o mundo (Chernaki; Almeida, 2001; ChernaKi-LefFer et al., 2001).

Larvas e adultos são ingeridos pelas aves nolugar de ração balanceada, influenciando o desenvolvimento das mesmas (Matias, 2005; Despins; Axtell, 1995). Além disso, podem contaminar a carcaça de frangos, quando são extraídos o papo e a moela nos abatedouros (CHernAKI-LefFer et al., 2001). O cascudinho também é considerado potencial vetor de vírus, bactérias, fungos, protozoários e helmintos em aviários (STEINKRAUS et al., 1992; GoODWIN; WALTMAN, 1996; MCAllister et al., 1995; CHERNAKI et al., 2002; VITTORI et al., 2006).

Diante da necessidade de se minimizar os problemas causados pela presença do inseto e devido à falta de métodos alternativos, os produtores dependem principalmente do controle químico para suprimir as populações de $A$. diaperinus nos aviários (LAMBKIN, 2005), sendo os inseticidas piretroides e organofosforados o método mais utilizado.

Além disso, para o manejo da praga, podem ser utilizados alguns inseticidas inibidores de cresci-

${ }^{2}$ Universidade Federal do Paraná, Departamento de Zoologia, Curitiba, PR, Brasil.

${ }^{3}$ Noxon Saúde Animal, Ponta Grossa, PR, Brasil. 
mento ou outras técnicas, como a de controle cultural (ARENDS, 1987; SAlin et al., 2003; LAMBKIN; Rice, 2007).

No entanto, o acúmulo de poeira sobre as superfícies tratadas do aviário reduz a eficácia de muitos tratamentos resultando em baixos níveis de controle e elevação no custo de produção, já que as aplicações, em geral, são onerosas (WEAVER; Kondo, 1987).

Uma preocupação adicional quanto à grande dependência de inseticidas químicos para o controle do cascudinho é o aparecimento de populações resistentes a esses inseticidas (TOMBERLIN et al., 2008), tal como constatado por CHERNAKI-LeFFer (2004) e LAMBKIN (2005).

Ouso de moléculas inseticidas combinadas pode ser uma alternativa para diminuir este problema, e segundo SALIN et al. (2003) esta estratégia apresenta resultados muito interessantes para o controle do cascudinho.

Neste sentido, éimportante que sejam realizados estudos para verificar a eficiência de novos produtos comerciais e princípios ativos combinados, bem como estratégias de aplicação e os níveis de controle em laboratório e campo.

Assim, este trabalho teve por objetivo avaliar a eficiência de um novo produto comercial, composto por uma mistura demoléculas inseticidas (piretroide, organofosforado e vegetal), visando a sua utilização no controle do cascudinho dos aviários (A. diaperinus).

\section{MATERIAL E MÉTODOS}

Avaliação em condições de laboratório. Foram utilizados insetos adultos de $A$. diaperinus coletados em aviário comercial sem tratamento químico por pelo menos dois lotes anteriores de aves, os quais foram mantidos em recipientes plásticos fechados com tampa perfurada, contendo cama de aviário e ração pra aves. Os insetos foram trazidos para o laboratório permanecendo por um período não superior a sete dias até a instalação dos experimentos.

Inicialmente, foram realizados experimentospiloto para estipular as concentrações a serem utilizadas com o produto Teste, utilizando-se como Padrão para comparação outro produto similar já existente no mercado para o controle do cascudinho em aviários (Tabela 1).

Assim, foram preparadas as cinco concentrações de cada um dos inseticidas, baseando-se na concentração final para cada litro deágua destilada da calda. No tratamento controle (testemunha) se aplicou somente água destilada.

Foram realizados dois experimentos, avaliandose o contato direto e indireto com os produtos. No primeiro, os produtos, nas respectivas concentrações foram pulverizados diretamente sobre os insetos, que foram divididos em cinco repetições com 50 insetos por concentração, sendo confinados em copos plásticos onde receberam $1 \mathrm{~mL}$ do tratamento por meio de um pulverizador acoplado a um compressor de ar. Após a aplicação, os insetos foram transferidos para placas de Petri e alimentados com ração comercial para frangos.

No segundo experimento, foi pulverizado $1 \mathrm{~mL}$ dos produtos nas concentrações já citadas, sobre a superfície interna de placas de Petri e 24 horas após a secagem, os insetos foram transferidos para as mesmas, incubando-os com ração para aves, sendo o número de insetos e de repetições, idêntico ao anterior. Todas as placas foram mantidas em potes plásticos no interior de uma câmara de incubação regulada para $26 \pm 1^{\circ} \mathrm{C}$ e fotofase de 14 horas. A avaliação foi realizada diariamente por 10 dias, anotando-se o número de adultos mortos (considerando inseto morto, os que se apresentavam totalmente inativos).

Tabela 1 - Dados técnicos dos produtos e concentrações utilizadas na comparação de eficiência para o controle de $A l$ phitobius diaperinus.

\begin{tabular}{|c|c|c|}
\hline \multirow{2}{*}{ Dados técnicos } & \multicolumn{2}{|c|}{ Inseticidas (Produtos comerciais) } \\
\hline & Padrão $\left(\right.$ Colosso $\left.^{\circledR}\right)$ & Teste (Couro limpo $\left.{ }^{\circledR}\right)$ \\
\hline \multirow{4}{*}{$\begin{array}{l}\text { Fórmula: composição em cada } 100 \text { mL } \\
\text { de produto }\end{array}$} & Cipermetrina.....15 g & Cipermetrina.....15 g \\
\hline & Clorpirifós........25 g & Clorpirifós........25 g \\
\hline & Citronelal............ $\mathrm{g}$ & Citronelal............ $\mathrm{g}$ \\
\hline & Veículo q.s.p....100 mL & Veículo q.s.p....100 mL \\
\hline Formulação & Concentrado emulsionável & Concentrado emulsionável \\
\hline Concentração indicada $(\mathrm{CI})^{*}$ & 2,5 L/1000 L de água & $1 \mathrm{~L} / 1000 \mathrm{~L}$ de água \\
\hline \multirow{5}{*}{$\begin{array}{l}\text { Concentrações utilizadas } \\
\text { (diluindo-se em } 1 \text { L de água) }\end{array}$} & A - $200 \%$ da CI $(5 \mathrm{~mL} / \mathrm{L})$ & $\mathrm{A}-200 \%$ a CI $(2 \mathrm{~mL} / \mathrm{L})$ \\
\hline & $\mathrm{B}-\mathrm{CI}(2,5 \mathrm{~mL} / \mathrm{L})$ & $\mathrm{B}-\mathrm{CI}(1 \mathrm{~mL} / \mathrm{L})$ \\
\hline & C - $50 \%$ da CI $(1,25 \mathrm{~mL} / \mathrm{L})$ & C - $50 \%$ da CI $(0,5 \mathrm{~mL} / \mathrm{L})$ \\
\hline & D - $25 \%$ da CI $(0,62 \mathrm{~mL} / \mathrm{L})$ & $\mathrm{D}-25 \%$ da $\mathrm{CI}(0,25 \mathrm{~mL} / \mathrm{L})$ \\
\hline & $\mathrm{E}-12,5 \%$ da CI $(0,31 \mathrm{~mL} / \mathrm{L})$ & $\mathrm{E}-12,5 \%$ da CI $(0,12 \mathrm{~mL} / \mathrm{L})$ \\
\hline
\end{tabular}

*Concentrações e volume de calda indicados na bula para aviários de frango de corte com $1200 \mathrm{~m}^{2}$. 
Os experimentos foram realizados em um delineamento inteiramente aleatorizado e os dados obtidos foram analisados estatisticamente quanto à variância sendo as médias comparadas entre si pelo teste de Tukey, a 5\% de significância e também submetidos ao programa PoloPC para estimativa da $\mathrm{CL}_{50}$.

Avaliação em condições de campo (Avaliação da eficiência de tratamento do solo). O experimento foi realizado em dois aviários comerciais de $1.200 \mathrm{~m}^{2}$ cada, localizados no Município de Cascavel, PR, integrados da Diplomata Comercial e Industrial Ltda., sendo o aviário localizado na linha Rio do Salto tratado com o produto teste e outro situado na Linha São Salvador, que não recebeu qualquer tratamento, considerado testemunha.

Na última semana de cada lote alojado, foi efetuada uma avaliação populacional de cascudinho nos aviários, em 14 pontos distintos: 4 junto aos pilares, 4 junto às muretas e 6 sob os comedouros, coletando-se em cada ponto uma amostra da cama de $30 \times 30 \mathrm{~cm}$ em total profundidade até o solo (GodinHo; Alves, 2009). As amostras foram peneiradas e o número de adultos registrado.

Após a retirada das aves e limpeza do aviário, efetuou-se a aplicação do produto teste em todas as superfícies internas do aviário, na concentração de $1 \mathrm{~L} / 1.000 \mathrm{~L}$ de água, sendo utilizados $1.000 \mathrm{~L}$ de água no tratamento de todo aviário, utilizando-se bico pulverizador acoplado em uma mangueira pressurizada pelo sistema existente no aviário.

Vale ressaltar que a concentração utilizada (1:1000) representa 2,5 vezes menos produtoaplicadonoaviário emrelaçãoà concentraçãorecomendada pelofabricante doproduto padrão, aquiconsiderado para comparação, conforme constam nas bulas dos produtos.

Após a aplicação o aviário foi mantido vazio por 5 dias, com as cortinas abaixadas por 48 horas, quando então se fez a abertura para ventilação, secagem e colocação da cama para novo alojamento das aves. No aviário controle, o procedimento de avaliação populacional foi o mesmo, porém, não foi realizada qualquer aplicação.

Realizou-se nova avaliação na última semana do alojamento do primeiro lote de aves, em ambos aviários, seguindo os mesmos procedimentos descritos anteriormente.

Os dados obtidos na primeira avaliação corresponderam à totalidade da população (100\%), e a avaliação subseqüente indicou o percentual de infestação em relação à população anterior. Os experimentos foram realizados em um delineamento inteiramente aleatorizado fazendo-se as análises estatísticas com o programa BioEstat 5.0, sendo as médias compradas entre si e submetidas ao teste de Kruskal-Wallis, ao nível de $5 \%$ de significância.

\section{RESULTADOS E DISCUSSÃO}

\section{Avaliação em condições de laboratório}

O produto teste apresentou o efeito mais rápido quando aplicado sobre o inseto, o qual atingiu a taxa de $80 \%$ de mortalidade dos insetos no primeiro dia de avaliação, na maior concentração testada (A - 200\% da $\mathrm{CI}$ ), alcançando o mesmo percentual com a concentraçãorecomendada3 diasapósa aplicação(DAA)(Fig.1).

Tal resposta foi superior ao produto padrão, o qual apresentou 1 DAA atividade contra $60 \%$ dos insetos no dobro da concentração recomendada e 40\% na concentração recomendada.

Ao final do período de avaliação, ambos os produtos se igualaram na concentração maior, porém, na concentraçãorecomendada, o produto testetevemaior eficiência em todas as avaliações, a partir do $2^{\circ}$ DAA.

Quanto ao efeito residual, verificou-se novamente maior efeito do produto teste, que provocou cerca de $70 \%$ de mortalidade 1 DAA, enquanto o produto padrão apenas $30 \%$ no mesmo período e na maior concentração (Fig. 2).

Ao final do período de avaliação, ambos os produtos se igualaram, na maior concentração, porém, na concentração recomendada, o produto teste foi mais eficiente, em todas as avaliações (a partir do segundo dia) chegando a ultrapassar o produto padrão (na concentração de $200 \%$ ) no quarto dia.

Comparando-se a atividade 10 DAA, em ambos os experimentos, observou-sequeoinseticida testeapresentou maior eficiência, provocando maior percentual de mortalidade nas duas estratégias testadas (Tabelas 2e 3 ). Além disso, para a aplicação direta, as concentrações 1, 2 e3nãoapresentaram diferença demortalidade depois de 10diase,considerandooefeitoresidual,estaigualdadefoi aindamaior, vistoquenenhumaconcentraçãodiferiupara oreferido produto, oque podeser considerado vantajoso do ponto de vista econômico e ambiental.

Considerando os dados informativos da bula de ambos os inseticidas utilizados, constata-se que apresentam a mesma formulação e, sendo assim, teriam que apresentar também resultados similares.

Um estudo semelhante foi realizado por Silva et al. (2007), porém, os insetos foram expostos ao mesmo produto aqui denominado padrão, por $24 \mathrm{~h}$, mas em concentrações mais elevadas do que as utilizadas no presente estudo, sendo a concentração indicada pelo fabricante a menor das testadas pelos autores. Nesse caso, alcançou-se $100 \%$ de mortalidade em todos os tratamentos.

Verificou-se que a $\mathrm{CL}_{50}$ e $\mathrm{CL}_{90}$ de ambos os produtos diferem, tanto entre eles, quanto em relação à forma de aplicação, sendo menor para o produto teste, na aplicação direta sobre o inseto. Tanto a $\mathrm{CL}_{50}$ como $\mathrm{CL}_{90}$ do produto testeforam 2,7 vezes menores na aplicação direta sobre o inseto e 4,8 vezes menores na avaliação residual, em relação ao obtido para o produto padrão (Tabela 4). 

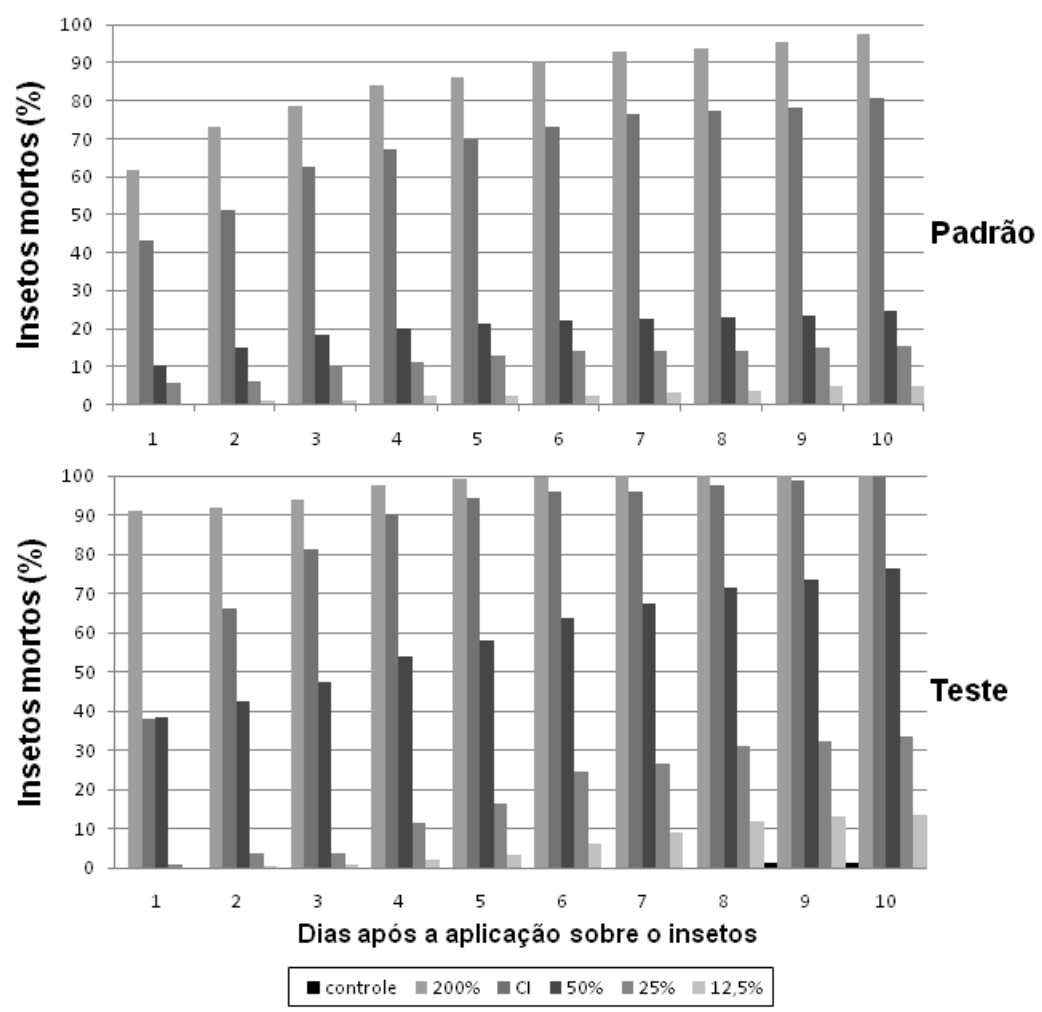

Fig. 1 - Porcentagem de mortalidade acumulada de Alphitobius diaperinus após 10 dias com aplicação pulverizada sobre o inseto. padrão (inseticida comercial padrão), teste (novo inseticida comercial testado); concentrações avaliadas: $200 \%$ da ci, ci (concentração indicada), $50 \%$ da CI, 25\% da CI e 12,5\% da CI, em ambos. Para padrão CI = 2,5 mL/L de água; para teste $\mathrm{CI}=1 \mathrm{~mL} / \mathrm{L}$ de água.
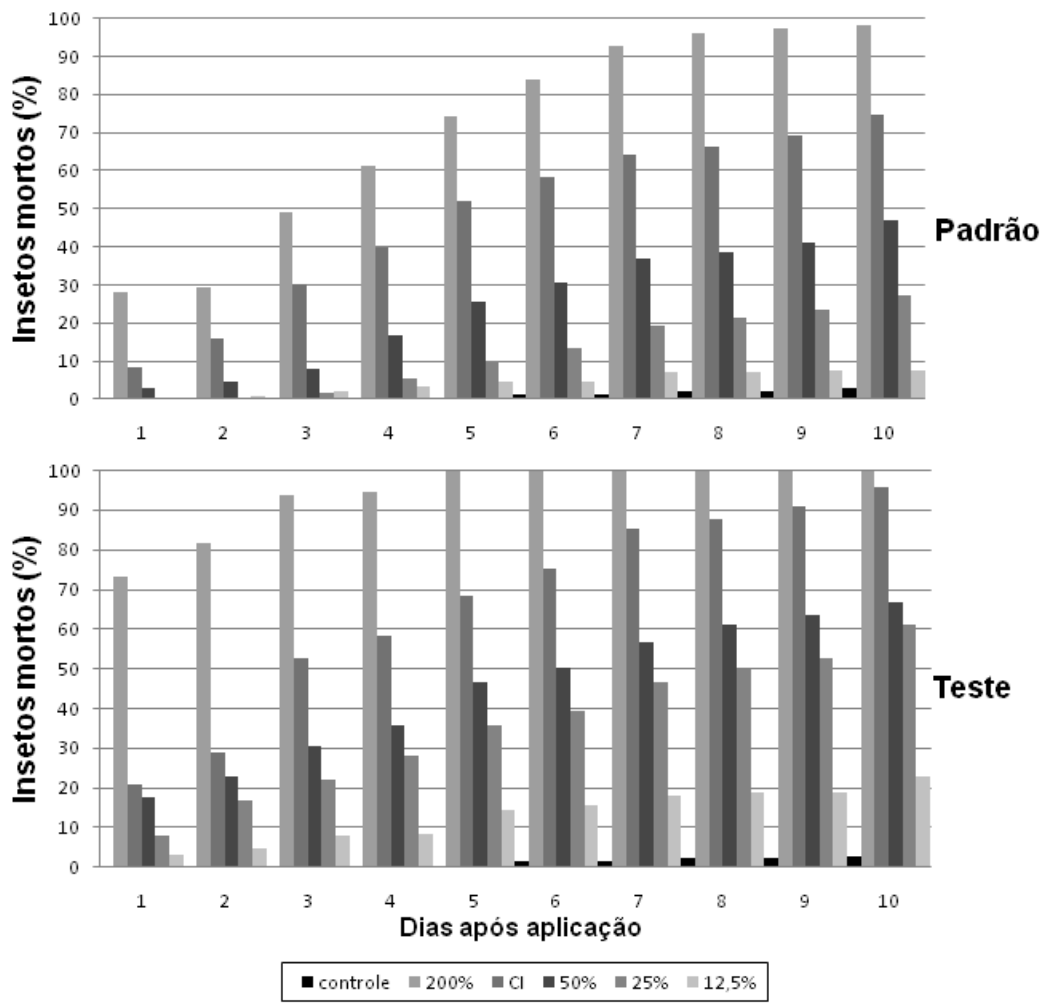

Fig. 2 - Porcentagem de mortalidade acumulada de Alphitobius diaperinus em 10 dias com aplicação pulverizada sobre a placa de Petri (verificação do poder residual). padrão (inseticida comercial padrão), teste (novo inseticida comercial testado); concentrações avaliadas: $200 \%$ da CI, CI (concentração indicada), $50 \%$ da CI, $25 \%$ da CI e $12,5 \%$ da CI, em ambos. Para padrão $\mathrm{CI}=2,5 \mathrm{~mL} / \mathrm{L}$ de água; para teste $\mathrm{CI}=1 \mathrm{~mL} / \mathrm{L}$ de água. 
Tabela 2 - Porcentagem de mortalidade de adultos do cascudinho (Alphitobius diaperinus), 10 dias após terem sido submetidos à aplicação direta de dois inseticidas químicos (Padrão ou Teste), em condições de laboratório (26 $\pm 2^{\circ} \mathrm{C}$, fotofase de 14 horas).

\begin{tabular}{lcc}
\hline \multirow{2}{*}{ Tratamento/Concentração } & \multicolumn{2}{c}{ Produto } \\
\cline { 2 - 3 } & Padrão & Teste \\
\hline Controle & $2,4 \pm 1,04 \mathrm{D} \mathrm{a}$ & $0,8 \pm 0,07 \mathrm{Da}$ \\
$200 \%$ da CI & $94,8 \pm 3,82 \mathrm{~A} \mathrm{a}$ & $98,8 \pm 0,71 \mathrm{~A} \mathrm{~b}$ \\
Concentração indicada* & $80,8 \pm 4,68 \mathrm{~B} \mathrm{a}$ & $99,6 \pm 0,36 \mathrm{~A} \mathrm{~b}$ \\
$50 \%$ da CI & $82,8 \pm 3,86 \mathrm{Ba}$ & $98,8 \pm 0,71 \mathrm{~A} \mathrm{~b}$ \\
$25 \%$ da CI & $52,0 \pm 5,03 \mathrm{C} \mathrm{a}$ & $78,0 \pm 5,42 \mathrm{~B} \mathrm{~b}$ \\
$12,5 \%$ da CI & $9,6 \pm 3,73 \mathrm{Da}$ & $49,6 \pm 6,80 \mathrm{C} \mathrm{a}$ \\
\hline
\end{tabular}

Médias ( \pm EPM) seguidas de mesma letra maiúscula na coluna e minúscula na linha não diferem entre si ao nível de $5 \%$ de significância pelo teste de Tukey.

*Para Padrão CI = 2,5 mL/L de água; para Teste CI = $1 \mathrm{~mL} / \mathrm{L}$ de água.

Tabela 3 - Porcentagem de mortalidade de adultos do cascudinho (Alphitobius diaperinus), 10 dias após caminhamento sobre superfície tratada com dois inseticidas químicos (Padrão ou Teste), em condições de laboratório $\left(26 \pm 2^{\circ} \mathrm{C}\right.$, fotofase de 14 horas).

\begin{tabular}{lcc}
\hline \multirow{2}{*}{ Tratamento/Concentração } & \multicolumn{2}{c}{ Produto } \\
\cline { 2 - 3 } & Padrão & Teste \\
\hline Controle & $4,8 \pm 2,01 \mathrm{C} \mathrm{a} \pm 2,63 \mathrm{~B} \mathrm{a}$ \\
$200 \%$ da CI & $100 \pm 0,00 \mathrm{~A} \mathrm{~b}$ & $100 \pm 0,00 \mathrm{~A} \mathrm{~b}$ \\
Concentração indicada* & $100 \pm 0,00 \mathrm{~A} \mathrm{~b}$ & $100 \pm 0,00 \mathrm{~A} \mathrm{~b}$ \\
$50 \%$ da CI & $98,4 \pm 1,43 \mathrm{~A} \mathrm{~b}$ & $100 \pm 0,00 \mathrm{~A} \mathrm{~b}$ \\
$25 \%$ da CI & $88,0 \pm 4,53 \mathrm{~B} \mathrm{a}$ & $99,2 \pm 0,71 \mathrm{~A} \mathrm{~b}$ \\
$12,5 \%$ da CI & $5,6 \pm 1,43 \mathrm{C} \mathrm{a}$ & $92,8 \pm 1,34 \mathrm{~A} \mathrm{~b}$ \\
\hline
\end{tabular}

Médias ( \pm EPM) seguidas de mesma letra maiúscula na linha e minúscula na coluna não diferem entre si ao nível de $5 \%$ de significância pelo teste de Tukey.

*Para padrão $\mathrm{CI}=2,5 \mathrm{~mL} / \mathrm{L}$ de água; para teste $\mathrm{CI}=1 \mathrm{~mL} / \mathrm{L}$ de água.

Tabela 4 - Valores da $\mathrm{CL}_{50}$ e $\mathrm{CL}_{90}$ para cada produto testado (em L de produto), transformadas para aplicação em 400 L de água.

\begin{tabular}{|c|c|c|c|c|c|}
\hline Tratamento & $\mathrm{n}^{*}$ & $x^{2 * *}$ & $\mathrm{gl}^{* * *}$ & $\begin{array}{c}\text { CL50 } \\
\text { (limite inferior - limite superior) }\end{array}$ & $\begin{array}{c}\text { CL90 } \\
\text { (limite inferior - limite superior) }\end{array}$ \\
\hline \multicolumn{6}{|l|}{ Padrão } \\
\hline Direto no inseto & 300 & \multirow{2}{*}{1,391} & 299 & $0,329(0,167-0,519)$ & $0,956(0,577-3,016)$ \\
\hline Superfície tratada & 300 & & 299 & $0,167(0,056-0,370)$ & $0,500(0,270-1,813)$ \\
\hline \multicolumn{6}{|l|}{ Teste } \\
\hline Direto no inseto & 300 & \multirow{2}{*}{1,626} & 299 & $0,124(0,053-0,178)$ & $0,367(0,256-0,819)$ \\
\hline Superfície tratada & 300 & & 299 & $0,035(0,039-0,098)$ & $0,106(0,027-0,305)$ \\
\hline
\end{tabular}

*tamanho da amostra; ${ }^{* *}$ valor do qui-quadrado; ${ }^{* * *}$ graus de liberdade.

Há ainda um aspecto econômico e ambiental que devem ser levados em consideração, a despeito de os experimentos terem sido realizados em laboratório. Segundo a estimativa, para se obter mortalidade de $90 \%$ sobre o inseto, utilizando o produto padrão devese aplicar aproximadamente $95 \%$ da concentração indicada no rótulo (aproximadamente $2,38 \mathrm{~mL} / \mathrm{L}$ de água). Enquanto que para se obter o mesmo resultado com o produto teste, utiliza-se aproximadamente
$37 \%$ da concentração indicada $(0,37 \mathrm{~mL} / \mathrm{L}$ de água), o que representa uma economia de produto sendo aplicado, com benefícios econômicos e ambientais.

Avaliação em condições de campo. Em ambos os aviários houve redução da população de adultos, resultante da ação do manejo do aviário, com a remoção da cama usada e colocação da cama nova. Vale ressaltar que no aviário não tratado, os pontos sob os comedouros sempre apresentaram maior número 
de insetos, enquanto que no tratado esta tendência não se repetiu em todo o aviário, sendo apenas nos comedouros de um dos lados (Tabelas 5 e 6).

De acordo com Godinho; Alves (2009), em condições normais, o maior acúmulo de insetos é sempre embaixo dos comedouros, encontrando-se menores quantidades em muretas e pilares, geralmente com números parecidos entre os dois. À medida que a população de cascudinhos aumenta dentro do aviário, ocorre elevação do número de insetos primeiramente sob os comedouros, com subseqüente aumento nas muretas.
Contudo,noaviário tratado, a redução populacional foi maior em todos os pontos amostrados, indicando a ação do produto aplicado. Além disso, a média da redução populacional foi de aproximadamente $75 \%$, entre os 3 locais de amostragem, estando próximo ao mínimo de 80\% recomendado por MERCosul/GMC (1996) para considerar eficiente o tratamento de inseticida em aviário de frango de corte (Tabela 7).

Também foi analisada a diferença na redução do número de insetos encontrados após aplicação e sua reinfestação, confirmando a ação do produto testado no aviário (Tabela 8).

Tabela 5 - Número de adultos do cascudinho (Alphitobius diaperinus) prévia e posteriormente à troca da cama e porcentagem de reinfestação, em um aviário não tratado com o produto teste. Cascavel, julho, setembro, 2007.

\begin{tabular}{|c|c|c|c|c|}
\hline Ponto de amostragem $^{1}$ & Prévia & Posterior & Reinfestação/ponto ${ }^{2}$ & Média/área ${ }^{3}$ \\
\hline $\begin{array}{l}\text { MD } 1 \\
\end{array}$ & 905 & 661 & 73,0 & \\
\hline MD 2 & 1183 & 378 & 32,0 & 52,5 \\
\hline CD 1 & 1775 & 756 & 42,6 & \\
\hline $\mathrm{CD} 2$ & 672 & 823 & 122,5 & 82,5 \\
\hline PD 1 & 1615 & 135 & 8,4 & \\
\hline PD 2 & 2136 & 323 & 15,1 & 11,7 \\
\hline PC 1 & 2165 & 1365 & 63,0 & \\
\hline PC 2 & 2482 & 6254 & 252,0 & 157,5 \\
\hline ME 1 & 3316 & 747 & 22,5 & \\
\hline ME 2 & 3057 & 1591 & 52,0 & 37,3 \\
\hline CE 1 & 1584 & 947 & 59,8 & \\
\hline CE 2 & 3434 & 2112 & 61,5 & 60,6 \\
\hline PE 1 & 1884 & --- & --- & \\
\hline PE 2 & 2720 & 810 & 29,8 & 14,9 \\
\hline
\end{tabular}

Tabela 6 - Número de adultos do cascudinho (Alphitobius diaperinus) prévia e posteriormente à troca da cama e porcentagem de reinfestação, em um aviário tratado com o produto teste. Cascavel, julho, setembro, 2007.

\begin{tabular}{|c|c|c|c|c|}
\hline Ponto de amostragem ${ }^{1}$ & Prévia & Posterior & Reinfestação/ponto ${ }^{2}$ & Média/área $^{3}$ \\
\hline MD 1 & 3389 & 655 & 19,3 & \\
\hline MD 2 & 3509 & 571 & 16,3 & 17,8 \\
\hline CD 1 & 1168 & 396 & 33,9 & \\
\hline CD 2 & 1039 & 769 & 74,0 & 54,0 \\
\hline PD 1 & 2141 & 355 & 16,6 & \\
\hline PD 2 & 2303 & 254 & 11,0 & 13,8 \\
\hline PC 1 & 1276 & 543 & 42,6 & \\
\hline PC 2 & 1694 & 70 & 4,1 & 23,3 \\
\hline ME 1 & 1641 & 759 & 46,3 & \\
\hline ME 2 & 4360 & 615 & 14,1 & 30,2 \\
\hline CE 1 & 2760 & 376 & 13,6 & \\
\hline CE 2 & 3160 & 540 & 17,1 & 15,4 \\
\hline PE 1 & 3106 & 37 & 1,2 & \\
\hline PE 2 & 1664 & 69 & 4,1 & 2,7 \\
\hline
\end{tabular}

$\overline{1,2,3}$ Valem as mesmas observações feitas para a Tabela 5. 
Tabela 7 - Comparação da infestação populacional de adultos do cascudinho (Alphitobius diaperinus) prévia e posteriormente à troca da cama, nos aviários controle e tratado com o produto teste, Cascavel, julho, setembro, 2007.

\begin{tabular}{lccc}
\hline & \multicolumn{2}{c}{ Períodos de amostragem } \\
\hline \multirow{2}{*}{ Ponto de amostragem } & \multicolumn{2}{c}{ Aviário controle } \\
\cline { 2 - 4 } & Prévia & Posterior & Reinfestação \\
\hline Mureta & $2115,2 \pm 539,82 \mathrm{~A}$ & $844,2 \pm 266,11 \mathrm{~A}$ & $44,9 \pm 9,70$ \\
Comedouro & $1716,2 \pm 521,51 \mathrm{~A}$ & $1159,5 \pm 277,09 \mathrm{~A}$ & $71,6 \pm 15,15$ \\
Pilar & $2167,1 \pm 148,21 \mathrm{~A}$ & $1551,6 \pm 873,82 \mathrm{~A}$ & $65,1 \pm 34,84$ \\
\hline & & Aviário tratado & \\
\cline { 2 - 4 } & Prévia & Posterior & $24,0 \pm 6,50$ \\
\hline Mureta & $3224,7 \pm 494,01 \mathrm{~A}$ & $650,0 \pm 34,80 \mathrm{~B}$ & $34,6 \pm 11,99$ \\
Comedouro & $2031,7 \pm 470,03 \mathrm{~A}$ & $520,2 \pm 78,46 \mathrm{~B}$ & $13,3 \pm 5,75$ \\
\hline
\end{tabular}

*Médias ( \pm EPM) seguidas de mesma letra maiúscula na linha não diferem entre si ao nível de 5\% de significância pelo teste de Kruskal-Wallis.

Tabela 8 - Comparação da infestação populacional de adultos do cascudinho (Alphitobius diaperinus) prévia e posteriormente à troca da cama, nos aviários controle e tratado com o produto teste, Cascavel, julho, setembro, 2007.

\begin{tabular}{lccc}
\hline \multicolumn{4}{c}{ Períodos de amostragem } \\
\hline Aviários & Prévia & Posterior & Reinfestação \\
\hline Controle & $2066,3 \pm 221,95^{*} \mathrm{~A} \mathrm{a}$ & $1237,4 \pm 396,22 \mathrm{~B} \mathrm{a}$ & $61,2 \pm 16,04$ a \\
Tratado & $2372,1 \pm 263,13 \mathrm{~A} \mathrm{a}$ & $429,2 \pm 64,20 \mathrm{~B} \mathrm{~b}$ & $22,4 \pm 5,18 \mathrm{~b}$ \\
\hline
\end{tabular}

*Médias ( \pm EPM) seguidas de mesma letra maiúscula na linha e minúscula na coluna não diferem entre si ao nível de $5 \%$ de significância pelo teste de Kruskal-Wallis.

Asegurançadoproduto Testepodeseratestada pelo estudorealizado porSiLvaetal.(2007), noqual os autores aplicaram o produto no aviário e também submeteram um grupo de as aves à alimentação forçada de adultos docascudinhotratados previamentecomoprodutoaqui denominadoTeste. Asavesnãoapresentaramalterações no comportamento e análises do fígado, músculos e gordura revelaram a presença de resíduos abaixo dos limites mínimos para detecçãono método $(0,05 \mathrm{mg} / \mathrm{kg})$.

\section{CONCLUSÕES}

O produto teste, na concentração de $1 \mathrm{~L} / 1000 \mathrm{~L}$ de água é eficiente no controle do cascudinho dos aviários (A. diaperinus), sendo comparável e até superior ao produto padrão recomendando-se assim, a sua utilização.

\section{REFERÊNCIAS}

ARENDS, J.J. Control, management of the litter beetle. Poultry Digest, v.28, p.172-176, 1987.

CHERNAKI, A.M.; ALMEIDA, L.M. Exigências térmicas, período de desenvolvimento e sobrevivência de imaturos de Alphitobius diaperinus (Panzer) (Coleoptera: Tenebrionidae). Neotropical Entomology, v.30, p.365-368, 2001.
CHERNAKI, A.M.; BIESDORF, S.M.; ALMEIDA, L.M.; LEFFER, E.V.B.; VIGNE, F. Isolamento de enterobactérias em Alphitobius diaperinus e na cama de aviários no oeste do estado do Paraná, Brasil. Revista Brasileira de Ciência Avícola, v.4, p.243-247, 2002.

CHERNAKI-LEFFER, A.M. Dinâmica populacional, estimativa da resistência a inseticidas e alternativas de controle para o cascudinho Alphitobius diaperinus (Panzer, 1797) (Coleoptera: Tenbrionidae). 2004. 123f. Tese (Doutorado) Universidade Federal do Paraná, Curitiba, 2004.

CHERNAKI-LEFFER, A.M.; LAZZARI, F.A.; LAZZARI, S.M.N.; ALMEIDA, L.M.. Controle do cascudinho. Avicultura Industrial, n.1025, p.22-25, 2001.

DESPINS, J.L.; AXTELL, R.C. Feeding behavior and growth of broiler chicks fed larvae of the darkling beetle, Alphitobius diaperinus. Poultry Science, v.74, p.331-336, 1995.

GODINHO, R.P.; ALVES, L.F.A. Método de avaliação de população de cascudinho (Alphitobius diaperinus) Panzer em aviários de frango de corte. Arquivos do Instituto Biológico, São Paulo, v.76, n.1, p.107-110, 2009. Disponível em: <http://www.biologico.sp.gov.br/ docs/arq/v76_1/godinho.pdf>.

GOODWIN, M.A.; WALTMAN, W.D. Transmission of Eimeria, viruses, and bacteria to chicks: Darkling beetles (Alphitobius diaperinus) as vector of pathogens. The Journal of Applied Poultry Research, v.5, p.51-55, 1996. 
LAMBKIN, T.A. Baseline responses of adult Alphitobius diaperinus (Panzer) (Coleoptera: Tenebrionidae) to fenitrothion, and susceptibility status of populations in Queensland and New South Wales, Australia. Journal Economic Entomology, v.98, p. 938-942, 2005.

LAMBKIN, T.A.; RICE, S.J. Baseline Responses of Alphitobius diaperinus (Coleoptera: Tenebrionidae) to spinosad, and susceptibility of broiler populations in Eastern and Southern Australia. Journal Economic Entomology, v.100, n.4, p.1423-1427, 2007

MATIAS, R.S. Controle de Alphitobius diaperinus com inseticidas piretróides e organofosforados em granjas avícolas no sul do Brasil. A Hora Veterinária, v.25, p.47-51, 2005.

McALLISTER, J.C.; STEELMAN, C.D.; NEWBERRY, L.A.; SKEELES, J.K. Isolation of infectious bursal disease virus from the lesser mealworm, Alphitobius diaperinus (Panzer). Poultry Science, v.74, p.45-49, 1995.

MERCOSUL/GMC/RES №76/96. Regulamento Técnico para Registro de Produtos Antiparasitários de uso Veterinário. Disponível em: <http:/ /ftp.unb.br/pub/ UNB/ipr/rel/bila/1996/880.pdf > . Acesso em: 20 fev. 2007.

SALIN, C.; DELETTRE, Y.R.; VERNON, P. Controlling the Mealworm Alphitobius diaperinus (Coleoptera:Tenebrionidae) in Broiler and Turkey Houses: Field Trials with a Combined Insecticide Treatment: Insect Growth Regulator and Pyrethroid. Journal Economic Entomology, v.96, n.1, p.126-130, 2003.
SILVA, G.S.; MICHELS, M.G.; TOMA, S.B.; TERRA, F.E.; SOARES, V.E.; COSTA, A.J Effectiveness of the compound chlorpyrifos+cypermethrin+citronellal against Alphitobius diaperinus. Laboratory analysis and residue determination in carcasses. Revista Brasileira de Ciência Avícola, v.9, n.3, p. 157-160, 2007.

STEINKRAUS, D.C.; W.M. BROOKS, C.G. GEDEN. Discovery of the neogregarine Farinocystis tribolii and naeugregarine in the lesser mealworm, Alphitobius diaperinus. Journal of Invertebrate Pathology, v.59, p.203-205, 1992.

TOMBERLIN, J.K.; RICHMAN, D.; MYERS, H.M. Susceptibility of Alphitobius diaperinus (Coleoptera: Tenebrionidae) from broiler facilities in Texas to four insecticides. Journal of Economic Entomology, v.101, n.2, p.480-483, 2008.

VITORI, J.; SHOCKEN-ITURRINO, R.P.; TROVÓ, K.P; RIBEIRO, C.A.M.; BARBOSA, G.G. Alphitobius diaperinus como veiculador de Clostridium perfringens em granjas avícolas do interior paulista - Brasil. Ciência Rural, v.37, n.3, p.894-896, 2006.

WEAVER, J.E.; KONDO, V.A. Laboratory evaluation of insect growth regulators in producing lesser mealworm mortality and egg infertility. Journal of Agricultural Entomology, v.4, p.233-245, 1987.

Recebido em 15/6/09

Aceito em 6/11/10 